\title{
Prediction of preterm birth and imminent spontaneous delivery: a management challenge for health care providers
}

Preterm birth is an important concern in child mortality and requires quality maternal and neonatal care. In 2010, 11\% of live births worldwide (15 million babies) occurred before 37 weeks of gestation were complete. Of these premature births, about $85 \%$ were moderate to late preterm babies (32-36 weeks), $10 \%$ were very preterm babies (28-31 weeks), and $5 \%$ were extremely preterm babies ( $<28$ weeks) [1]. To understand better the extent of problems associated with preterm birth, improved documentation and reporting of the condition by health systems are needed globally [2].

There are many risk factors for preterm labor and delivery, including a history of spontaneous preterm birth, sociodemographic, obstetrical, psychological, genetic, and environmental factors [1]. Some are reversible, while others are not readily manageable [3]. Early identification of reversible risk factors may lead to better management and prevent this complication.

Prior preterm birth is the strongest risk factor for future preterm birth [4]. To reduce the risk of preterm birth, patients with prior preterm birth should be advised to cease tobacco and substance abuse, control underlying maternal comorbidities such as diabetes, and aim for a healthy body mass index. Planned pregnancies and appropriate interpregnancy intervals are highly recommended for multiparous mothers. Screening for and treatment of infections, appropriate nutrition, and more frequent prenatal care are also required [4]. Serial cervical length screening and warranted progesterone supplementation may be beneficial $[4,5]$. Several guidelines are available for management of potential preterm birth, including cervical length determination by transvaginal ultrasound examination at midtrimester and appropriate treatment if warranted $[6,7]$. Smoking cessation and lifestyle changes can reduce the risk of preterm birth [8].
In this issue, Chawanpaiboon et al. [9] provide evidence that combining cervical length from $15 \mathrm{~mm}$ to $30 \mathrm{~mm}$ with testing for placental $\alpha$-microglobulin-1 (PAMG-1) in cervicovaginal fluid has a high accuracy to predict imminent spontaneous delivery in women with preterm labor. In women with a short cervix, testing for the PAMG-1 amniotic fluid biomarker can assist providers to advise mothers to avoid triggers of spontaneous preterm delivery [10]. Whether or not the strategy will be effective in guiding management needs further evidence from clinical studies.

Because ample evidence suggests that cervical length as determined by transvaginal ultrasound examination simply identifies the risk for preterm birth, the procedure is advocated as a standard to care for women at risk of preterm birth. These women may benefit from corticosteroids, but they are best avoided if spontaneous delivery is not imminent. Asymptomatic women at risk should be screened at 2 week intervals starting from 16 weeks to 18 weeks, up to 24 weeks, and repeat ultrasound can improve predictive values and help avoid unwanted consequences of preterm pregnancy and delivery [11]. Adding a PAMG-1 test result may improve the accuracy of the prediction [9].

\section{References}

[1] Torchin H, Ancel P-Y. Épidémiologie et facteurs de risque de la prématurité [Epidemiology and risk factors of preterm birth]. J Gynecol Obstet Biol Reprod (Paris). 2016; 45:1213-30. [in French, English abstract]

[2] Chawanpaiboon S, Vogel JP, Moller A-B, Lumbiganon P, Petzold M, Hogan D, et al. Global, regional, and national estimates of levels of preterm birth in 2014: a systematic review and modelling analysis. Lancet Glob Health. 2019; 7:e37-46. doi: 10.1016/ S2214-109X(18)30451-0

*Correspondence to: Editorial Office of Asian Biomedicine, Faculty of Medicine, Chulalongkorn University, Bangkok 10330, Thailand, email:abmjournal@chula.ac.th

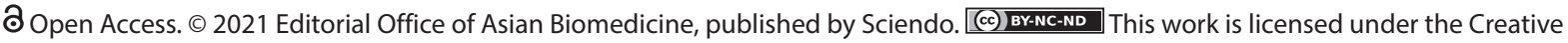
Commons Attribution NonCommercial-NoDerivatives 4.0 License. 
[3] Lamont RF. Advances in the prevention of infection-related preterm birth. Front Immunol. 2015; 6:566. doi: 10.3389/fimmu.2015.00566

[4] Colicchia LC, Simhan HN. Optimizing subsequent pregnancy outcomes for women with a prior preterm birth. Am J Perinatol. 2016; 33:267-75.

[5] Patel SS, Ludmir J. Drugs for the treatment and prevention of preterm labor. Clin Perinatol. 2019; 46:159-72.

[6] Medley N, Poljak B, Mammarella S, Alfirevic Z. Clinical guidelines for prevention and management of preterm birth: a systematic review. BJOG. 2018; 125:1361-9.

[7] American College of Obstetricians and Gynecologists. ACOG Practice Bulletin No. 142: Cerclage for the management of cervical insufficiency. Obstet Gynecol. 2014; 123(2 Pt 1):372-9.
[8] Matei A, Saccone G, Vogel JP, Armson AB. Primary and secondary prevention of preterm birth: a review of systematic reviews and ongoing randomized controlled trials. Eur J Obstet Gynecol Reprod Biol. 2019; 236:224-39.

[9] Chawanpaiboon S, Titapant V, Pooliam J. Placental $\alpha$-microglobulin-1 in cervicovaginal fluid and cervical length to predict preterm birth by Thai women with symptoms of labor. Asian Biomed (Res Rev News). 2021; 15:119-27.

[10] Hernández-Díaz S, Boeke CE, Romans AT, Young B, Margulis AV, McElrath TF, et al. Triggers of spontaneous preterm delivery - why today? Paediatr Perinat Epidemiol. 2014; 28:79-87.

[11] Ville Y, Rozenberg P. Predictors of preterm birth. Best Pract Res Clin Obstet Gynaecol. 2018; 52:23-32. 